\begin{tabular}{|c|c|c|}
\hline \multirow{3}{*}{$\begin{array}{r}\text { Case Reports in } \\
\text { Gastroenterology }\end{array}$} & \multirow{2}{*}{\multicolumn{2}{|c|}{ Case Rep Gastroenterol 2016;10:808-813 }} \\
\hline & & \\
\hline & $\begin{array}{l}\text { DOI: 10.1159/000454984 } \\
\text { Publisnea onine: January 6, } 2017\end{array}$ & $\begin{array}{l}\text { (c) } 2016 \text { The Author(s) } \\
\text { Published by S. Karger AG, Basel } \\
\text { www.karger.com/crg }\end{array}$ \\
\hline & \multicolumn{2}{|c|}{$\begin{array}{l}\text { This article is licensed under the Creative Commons Attribution-NonCommercial } 4.0 \\
\text { International License (CC BY-NC) (http://www.karger.com/Services/OpenAccessLicense). } \\
\text { Usage and distribution for commercial purposes requires written permission. }\end{array}$} \\
\hline
\end{tabular}

\title{
Liver Transplantation for Unresectable Metastases from Colon Adenocarcinoma
}

\author{
Luis Armando Caicedo Diego Buitrago Laura S. Thomas \\ Jorge I. Villegas Mauricio Duque Oscar Serrano Ana M. Arrunategui \\ Juan Guillermo Restrepo Gabriel Jaime Echeverri \\ Clinical Research Center, Fundación Valle del Lili, Center for Research in Advanced \\ Surgery and Transplants (CICAT), ICESI University, Cali, Colombia
}

\section{Keywords}

Colorectal cancer · Liver metastases · Liver transplantation · Recurrence · Survival rate

\begin{abstract}
Liver transplantation is an option that improves quality of life and prolongs life expectancy in patients with different types of liver disease. Liver transplantation is controversial for colorectal metastases and is not recommended in clinical practice guidelines. In this case report, we present, to our knowledge, the first liver transplantation for colorectal metastases conducted in Colombia, with a successful follow-up of more than 2 years. Patients with these characteristics who underwent liver transplantation experience reduced mortality and exponentially improved quality of life.

(c) 2016 The Author(s) Published by S. Karger AG, Basel
\end{abstract}

\section{Introduction}

Liver transplantation improves the quality of life and prolongs the life expectancy of patients with various types of liver disease [1,2]. Liver transplantation for colorectal metastases is, however, controversial and is not recommended in clinical practice guidelines $[1,3]$. 
Approximately $50 \%$ of patients presenting colorectal cancer have liver and pulmonary metastases [3]. Nowadays, patients with liver metastases are treated with neoadjuvant chemotherapy and then undergo local resection [4]. This treatment has a 5-year survival rate of $30-58 \%$, with a high rate of recurrence [3-6]. If the metastases are unresectable, the survival rate does not exceed $2 \%$ [4].

In the early 1990s, several studies of liver transplantation for colorectal metastases were conducted with poor outcomes, so this practice was abandoned [2]. Today, liver transplantation for colorectal metastases opens the doors for patients who do not have an adequate therapeutic alternative and has been shown to improve survival. This report presents the case of a young patient with colorectal cancer with unresectable liver metastases who received a liver transplantation, with no recurrences 2 years after transplantation.

\section{Case Presentation}

A 50-year-old previously healthy Hispanic female presented with a 20-day history of evolution of pain in the right hypochondrium, associated with a feeling of weight in the abdomen, and dysphagia. At physical examination, she presented with multiple palpable nodules in the liver, with no other associated symptoms. A CT scan of the abdomen taken showed hepatomegaly with images suggestive of liver metastases with no obvious primary tumor. Laboratory data included: CA 125, $57.84 \mathrm{U} / \mathrm{mL}$; CA 15.23, $27.34 \mathrm{U} / \mathrm{mL}$; CA 19.9, $21.5 \mathrm{U} / \mathrm{mL} ; \alpha$-fetoprotein, $6.94 \mu \mathrm{g} / \mathrm{mL}$; and carcinoembryonic antigen, $1,051.47 \mu \mathrm{g} / \mathrm{L}$.

A liver biopsy performed on 21.08.2013 led to the diagnosis of metastatic adenocarcinoma with no known primary and with KRAS negative (Fig. 1). A colonoscopy performed on 22.08.2013 found an ulcerated neoplastic mammillated lesion located $16-20 \mathrm{~cm}$ from the rectosigmoid junction that occupied $<50 \%$ of the colonic circumference. A biopsy was taken which led to the diagnosis of moderately differentiated infiltrative adenocarcinoma.

The therapeutic approach was neoadjuvant chemotherapy with bevacizumab, oxaliplatin, and capecitabine, with good tolerance. FOLFIRI plus cetuximab was also begun, and the patient received 9 doses every 2 weeks with grade IV dermal toxicity, so it was discontinued. She underwent sigmoid colon resection, with a finding of minimal residual disease with the following tumor pathology report: moderately differentiated adenocarcinoma, ulcerated and infiltrating to the limit between the adventitia and adipose tissue without perforation and with free resection edges. The degree of tumor regression was moderate. Regional lymph nodes were negative. Additional radioablation of the metastatic liver lesions was performed. In September 2013, the patient was hospitalized in order to begin the transplantation protocol.

To obtain a better characterization of the lesions, MRI of the pre-transplantation abdomen was carried out. Multiple nodular lesions were found, distributed in both hepatic lobes. The largest were located in segments IV-A, VI and VII. These lesions, of heterogeneous signal intensity, were found to be predominantly of high intensity in T2-weighted sequences and with low signal intensity in T1-weighted sequences, conditioning a restriction in diffusion sequences. Prior to the implementation of the contrast, a heterogeneous enhancement was shown in the larger areas, in the later phases, which, in the cancer context, suggest disseminated injuries (Fig. 2). In August 2014, a PET scan was carried out with the findings of hypermetabolic neoplastic injury type compromising the fifth segment of the liver.

In March 2014, liver resection was unsuccessfully attempted due to the location of the lesions, the tumor compromised the falciform ligament, left hepatic vein, and middle hepatic 
vein. The patient presented neuropathy secondary to 8 cycles of oxaliplatin and, as such, the protocol of irinotecan plus fluoropyrimidine plus cetuximab was continued.

On 13.11.2014, the patient underwent liver transplantation, from a 22-year-old male cadaveric donor, in cold ischemia for $7.5 \mathrm{~h}$. Her explant revealed no evidence of neoplastic cells. She had adequate clinical evolution and paraclinical signs in their postsurgical examination, with immunosuppressive management with tacrolimus $8 \mathrm{mg} /$ day, mycophenolate $2 \mathrm{~g} /$ day, and prednisolone $20 \mathrm{mg} /$ day, with a gradual decline in this medication until its suspension after 3 months. From March 2015 on, management was with everolimus $1 \mathrm{mg}$ every $12 \mathrm{~h}$ and tacrolimus $8 \mathrm{mg} /$ day, with the main objective of minimizing the doses of calcineurin inhibitor and potentiating the antineoplastic effect of everolimus. Prophylactic treatment was begun with valganciclovir and trimethoprim/sulfamethoxazole.

Posttransplant follow-up is monthly with oncology, transplant surgeons, and hepatology with laboratory results of liver, hepatic function, and plasma levels of immunosuppressants, and quarterly with abdominal MRI. At 19-month follow-up, the patient showed no evidence of liver recurrence; she remains asymptomatic and completely functional.

\section{Discussion}

Liver transplantation for colorectal metastases is a rarely implemented treatment and, in the global management guides, is not recommended as a therapeutic strategy. Our article describes the case of a young patient with an initial diagnosis of unresectable liver colorectal metastases. Medical management was initiated with neoadjuvant chemotherapy. She later received a liver transplant in our institution, with a satisfactory clinical evolution, in that she is still disease-free 2 years after transplant. The decision to undertake the transplantation was based on the age and functionality of the patient before the cancer advanced, the fact that she had no other treatment options, the location of the lesions, also the control of the primary tumor, the availability of organs, and the short waiting list for transplants at the Fundación Valle del Lili in Cali, Colombia.

In Norway, a prospective study was performed with patients who received a liver transplant, and a 5-year survival of $60 \%$ was found, with no recurrence of the disease [2, 3]. The research shows that these patients have survival rates that are close to those of patients transplanted for other, more widely accepted, diseases (such as hepatocellular carcinoma and cirrhosis). These findings are upheld even in patients with tumor recurrences outside of the transplanted organ: in comparison with resected patients, who face a tumor recurrence in the liver, transplanted patients generally have a better prognosis [7].

Recurrences after liver transplantation occur due to disseminated disease and usually present with a more benign evolution [8]. Surgical interventions in these lesions have a within-surgery mortality of close to zero and low perioperative mortality [7]. In addition, a comparative study was undertaken, looking at the use of chemotherapy as the sole treatment versus neoadjuvant chemotherapy and liver transplantation in patients who present with unresectable disease, with results showing a 5-year survival rate of 9 vs. $56 \%[4,9]$.

Given the low number of patients in these studies, compared to the global experience of resected liver metastases, further studies are required to determine whether this type of pathology could be absolute indication for liver transplantation. This possibility is, however, not available in the great majority of countries with consolidated organ donation systems, given the poor availability of organs due to the low rates of donation, and the fact that the systems require that the organs available be used for medically accepted indications only. As 
proposed by other authors, this opens up a possible field of study for the use of cross-border organs, supported by the fact that with the current management protocols, the 5-year survival rate for palliative unresectable pathologies does not exceed $10 \%[1,3]$.

\section{Conclusion}

This case is, to our knowledge, the first conducted in Colombia and the first with a successful follow-up of more than 2 years. We believe that liver transplantation is a valid and successful strategy for patients with unresectable liver disease of colorectal origin. Preliminary survival rates in the SECA study suggest that, in unresectable metastases of colorectal cancer, liver transplantation reduces mortality and exponentially improves the quality of life of patients [2]. Additionally, the Nordic experience offers a very hopeful panorama.

Due to medical advances in imaging, multimodal treatment for metastases, and the adequate selection of patients, 5-year survival rates are expected to be much greater than the current survival rates $[2,9]$.

\section{Statement of Ethics}

The authors complied with the ethical guidelines for authorship and publishing in the journal Case Reports in Gastroenterology. They declare that the subject in this case report gave informed consent and that the investigation was approved by the ethics committee of the Fundación Valle del Lili.

\section{Disclosure Statement}

The authors certify that they have no affiliations with or involvement in any organization or entity with any financial interest (such as honoraria; educational grants; participation in speakers' bureaus; membership, employment, consultancies, stock ownership, or other equity interest; and expert testimony or patent-licensing arrangements) or nonfinancial interest (such as personal or professional relationships, affiliations, knowledge, or beliefs) in our investigation. No funding was received for the writing of this paper.

\section{References}

1 European Association for the Study of the Liver: EASL Clinical Practice Guidelines: Liver transplantation. J Hepatol 2016;64:433-485.

- Foss A, Adam R, Dueland S: Liver transplantation for colorectal liver metastases: revisiting the concept. Transpl Int 2010;23:679-685.

-3 Hagness M, Foss A, Line PD, Scholz T, Jørgensen PF, Fosby B, Boberg KM, Mathisen O, Gladhaug IP, Egge TS, Solberg S, Hausken J, Dueland S: Liver transplantation for nonresectable liver metastases from colorectal cancer. Ann Surg 2013;257:800-806.

-4 Dueland S, Guren TK, Hagness M, Glimelius B, Line PD, Pfeiffer P, Foss A, Tveit KM: Chemotherapy or liver transplantation for nonresectable liver metastases from colorectal cancer? Ann Surg 2015;261: 956-960.

5 Simmonds PC, Primrose JN, Colquitt JL, Garden OJ, Poston GJ, Rees M: Surgical resection of hepatic metastases from colorectal cancer: a systematic review of published studies. Br J Cancer 2006;94: 982-999.

-6 McNally SJ, Parks RW: Surgery for colorectal liver metastases. Dig Surg 2013;30:337-347. 


\section{Case Reports in \\ Gastroenterology}

\begin{tabular}{l|l}
\hline Case Rep Gastroenterol 2016;10:808-813 \\
\hline DOI: 10.1159/000454984 & $\begin{array}{l}\text { C 2016 The Author(s). Published by S. Karger AG, Basel } \\
\text { www.karger.com/crg }\end{array}$ \\
\hline
\end{tabular}

Caicedo et al:: Liver Transplantation for Unresectable Metastases from Colon Adenocarcinoma

7 Adam R, de Gramont A, Figueras J, Kokudo N, Kunstlinger F, Loyer E, Poston G, Rougier P, Rubbia-Brandt L, Sobrero A, Teh C, Tejpar S, Van Cutsem E, Vauthey JN, Påhlman L; of the EGOSLIM (Expert Group on OncoSurgery management of LIver Metastases) group: Managing synchronous liver metastases from colorectal cancer: a multidisciplinary international consensus. Cancer Treat Rev 2015;41:729-741.

-8 Hagness M, Foss A, Egge TS, Dueland S: Patterns of recurrence after liver transplantation for nonresectable liver metastases from colorectal cancer. Ann Surg Oncol 2014;21:1323-1329.

-9 de Jong MC, Mayo SC, Pulitano C, Lanella S, Ribero D, Strub J, Hubert C, Gigot JF, Schulick RD, Choti MA Aldrighetti L, Mentha G, Capussotti L, Pawlik TM: Repeat curative intent liver surgery is safe and effective for recurrent colorectal liver metastasis: results from an international multi-institutional analysis. J Gastrointest Surg 2009;13:2141-2151.

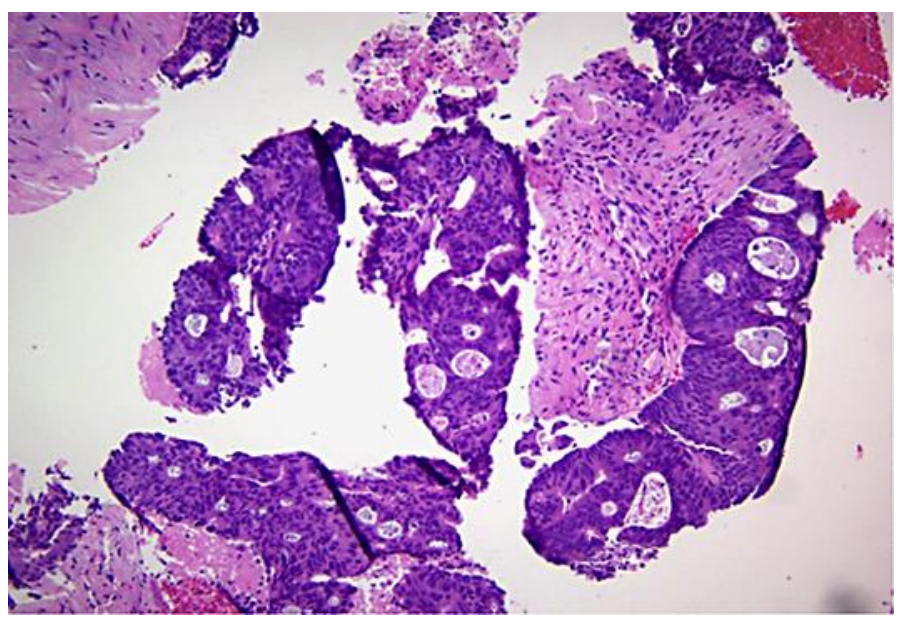

Fig. 1. Hepatic metastases from colon adenocarcinoma. Hematoxylin-eosin. $\times 200$. Fundación Valle del Lili. 


\begin{tabular}{|c|c|c|}
\hline \multirow{2}{*}{$\begin{array}{r}\text { Case Reports in } \\
\text { Gastroenterology }\end{array}$} & \multicolumn{2}{|c|}{ Case Rep Gastroenterol 2016;10:808-813 } \\
\hline & DOI: $10.1159 / 000454984$ & 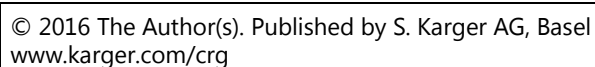 \\
\hline
\end{tabular}
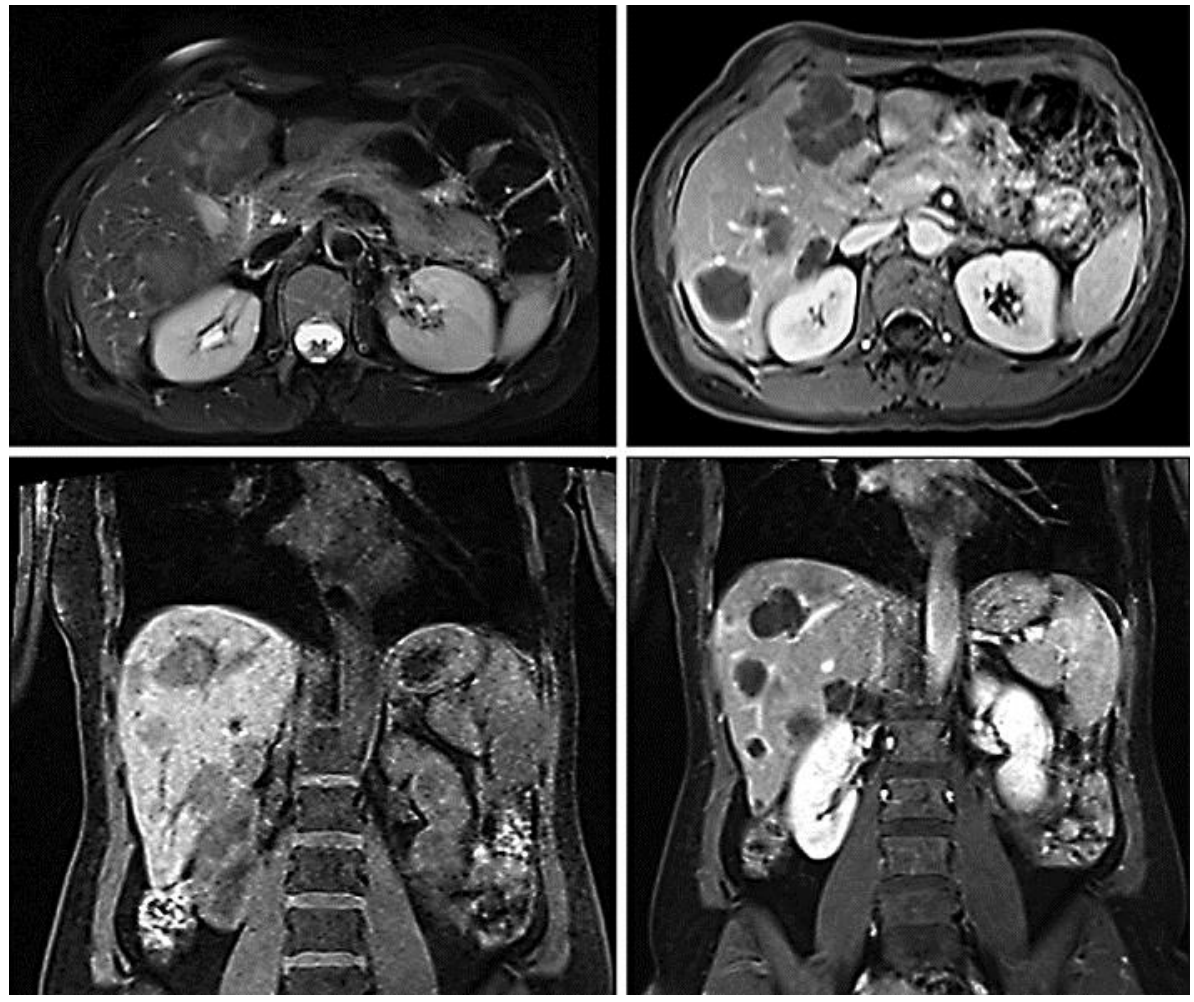

Fig. 2. MRI showing hepatic metastases. 